\title{
Electrochemistry in nanotechnology
}

\author{
M. Lakatos-Varsányi \\ Bay Zoltán Nonprofit Ltd, 1116 Budapest, Kondorfa utca 1., Hungary \\ E-mail:magda.lakatos@bayzoltan.hu
}

\begin{abstract}
Corrosion results in short- or long-term deterioration of materials. All over the world, researchers and engineers try to find better and better resolution to inhibit these undesired processes. One of the very efficient techniques, when the metal surface is covered by nanolayers, that can control the corrosion, is the deposition of solids by metal layers with predefined characteristics (composition, thickness, etc.) Among the many electrochemical processes, we have applied the non-stationary electrochemical method, named pulse current electrochemical deposition (PC-technique) for nanostructured thin layers deposition. Applying a current interruption method, we produced pure metal and alloy coatings with various compositions and layer thickness developed from aqueous solutions, at ambient temperature. The exceptional advantage of pure metal coatings produced by PC technique is the pore free, nano-sized structure. All technical details are summarized in this paper and the anticorrosion efficiency of the nanocoatings is demonstrated, too.
\end{abstract}

Key words: pulse current electrochemical deposition, metal (Fe, $\mathrm{Ni}$ ) and alloy (Ni-Co, $\mathrm{Fe}-\mathrm{P}$ ) coating, anticorrosion activity.

Received: April 1, 2016. Published: April 23, 2016.

doi: $\underline{10.17675 / 2305-6894-2016-5-2-6}$

\section{Introduction}

\subsection{Kinetics and mechanism of electrodeposition}

Electrodeposits of metals and alloys are frequently used for corrosion protection, improvement of decorative appearance of metals and development of unique functional properties [1-4]. Cathodic deposition of metals are usually is performed by direct current electrolysis from metal ion containing electrolytes. Electroplating is a common, cost effective technique for functional coatings. There are many different ways to deposit metals and alloys. One can control the composition of the deposited alloy furthermore this technique provides a simple way to monitor the thickness of electrodeposited layers; therefore it is a simple on-line method for quality control. It owns precisely controllers room temperature operation, lower energy requirements, faster deposition rates, and deposition over complicated shapes. Nowadays the electrochemical deposition can be performed by pulse current or by pulse electrode potentials. The plan of this technology has been known for some decades, but it came into general practice when the electronics and the computer technology provided the background for this technology. Pulse plating-as 
alternative to direct current electrolysis- is a versatile technique to prepare nanostructured thin film or nanocoatings.

Pulse plating technology [5-8] applies square wave signals varying the pulse parameters on time, off-time and pulse current density / or pulse electrode potentials (Figure 1). The control of electrode potentials requires experimental setup of electrochemical cell with three electrodes.
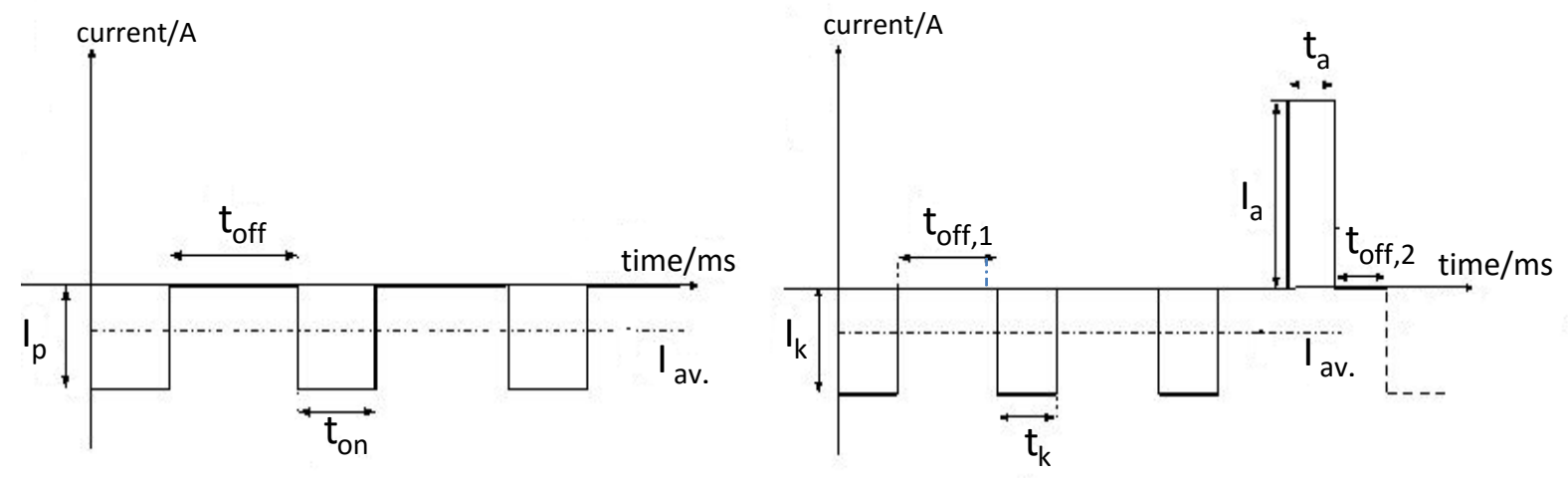

Figure 1. Typical pulse current waveforms.

The average current density $\left(\mathrm{I}_{\mathrm{av}}\right)$ can be expressed by the Eq. (1).

$$
I_{\text {av. }}=I_{\mathrm{p}} \cdot \frac{t_{\text {on }}}{t_{\text {on }}+t_{\text {off }}}=I_{\mathrm{p}} \cdot \gamma=I_{\mathrm{p}} \cdot t_{\text {on }} \cdot f,
$$

where $\gamma$ is the duty cycle that corresponds to the percentage of time period of pulse and the total time of a cycle and is given by Eq. (2).

$$
\gamma=\frac{t_{\text {on }}}{t_{\text {on }}+t_{\text {off }}} .
$$

The average current density in pulse plating is represented by dotted lines in Figure 1. The frequency $(f)$ is defined as the reciprocal of the cycle time:

$$
f=\frac{1}{T}=\frac{1}{t_{\mathrm{on}}+t_{\text {off }}} .
$$

The grain size, the morphology and the properties of the pulse-plated deposits are influenced by changing the pulsed parameters. Besides the pulse parameters, the composition of electrolyte and its temperature has also influence on the morphology and the grain size of the coatings.

In fact, the process of electrodeposition is a complex procedure, involving a number of intermediate stages. The most important of these are:

- diffusion of metallic ions from the bulk of solutions to the interface

- charge transfer at the electrode 
- partial or total loss of the solvate sheath and formation of adatoms at the electrode

- surface motion of these adsorbed adions, adatoms

- formation of clusters

\subsection{Pulse deposition of individual metals}

Most frequently, the baths used in the conventional galvanic procedures can be applied for pulse plating of metal coatings. Pulse plating can decrease the average grain size of metal coatings by orders of magnitude down to nano-crystallinite. The bath composition and the bath temperature have also influence on the grain size and properties of nanostructured metal coatings. These layers provide improved properties such as higher hardness, better homogeneity and corrosion resistivity.

\section{Experimental}

\subsection{Pulse plating of Ni layers}

Nickel coatings were deposited by short current pulses onto polished copper surface from three different electrolytes. Nanostructured metals are expected to form by means of electrochemical deposition, when large numbers of nuclei on the electrode surface are created, and if the growth of nuclei and crystallites are strongly impeded. In our experiments the period of $t_{\mathrm{ON}}$ (on-time) was $1 \mathrm{~ms}$ in most cases. Current density $(j)$ was altered between 0.5 and $1 \mathrm{~A} / \mathrm{cm}^{2}, t_{\text {off }}$ was varied between 100 and $250 \mathrm{~ms}$. These phenomena are reachable through application of grain growth, and new nuclei can form on the surface. The deposition was taken place at $40^{\circ} \mathrm{C}$, platina-mesh acted as an anode material. Any cases the NI depositions have been carried out by pulse plating techniques, which applies a square waveform and supply peaks up to a current density of $1 \mathrm{~A} / \mathrm{cm}^{2}$. The off-time pulse parameter $\left(t_{\mathrm{off}}\right)$ was varied between $100 \mathrm{~ms}$ and $250 \mathrm{~ms}$. Pulse on time $\left(t_{\mathrm{on}}\right)$ was $1 \mathrm{~ms}$ in any case. The composition of electrolyte as well as the optimum plating conditions namely $\left(t_{\mathrm{on}}\right)$ and $\left(t_{\mathrm{off}}\right)$ and peak current density $\left(I_{\mathrm{p}}\right)$, was systematically studied to synthesize Ni coatings with the smallest grain size.

The deposits were obtained from Watts-solution (based on $\mathrm{NiCl}_{2} \cdot 6 \mathrm{H}_{2} \mathrm{O}, \mathrm{NiSO}_{4} \cdot 7 \mathrm{H}_{2} \mathrm{O}$ and $\mathrm{H}_{3} \mathrm{BO}_{4}$ ) and from Watt's solution containing $\mathrm{Na}$ saccharin. K-Na-tartarate containing solution was also applied to examine the influence of different electrolytes.

\subsection{Pulse plating of Fe coatings}

Iron coatings were deposited by short current pulses onto polished $\mathrm{Cu}, \mathrm{Ti}, \mathrm{Al}$ and $\mathrm{Fe}$ surfaces from iron-sulphate and chloride containing electrolytes. The exact composition and operation conditions of solutions are given in Table 1.

In order to enhance the removal of hydrogen bubbles from the cathode surface that is co-deposited with the iron, wetting agent was added to the solutions. This type of additive decreases the surface tensile. All of electrolyte contains Fe(II) compounds. To prevent the oxidation of $\mathrm{Fe}$ (II) ions and save the stability of electrolyte, Ar gas was bubbled through 
the solutions during the operation of the electrolyte. All parameters are summarized in Table 1.

Table 1. Parameters used in the metal deposition.

\begin{tabular}{|c|c|c|c|c|}
\hline \multicolumn{5}{|c|}{ Concentration $\left[\mathrm{mol} / \mathrm{dm}^{3}\right]$} \\
\hline Components & 1. & 2. & 3. & 4. \\
\hline $\mathrm{FeSO}_{4} \cdot 7 \mathrm{H}_{2} \mathrm{O}$ & 0.75 & 0.75 & 0.75 & - \\
\hline $\mathrm{FeCl}_{2} \cdot 4 \mathrm{H}_{2} \mathrm{O}$ & 0.25 & 0.25 & 0.54 & 0.05 \\
\hline $\mathrm{NH}_{4} \mathrm{Cl}$ & 20 & & - & 0.5 \\
\hline$\left(\mathrm{NH}_{4}\right)_{2} \mathrm{SO}_{4}$ & - & 0.37 & - & - \\
\hline $\mathrm{H}_{3} \mathrm{BO}_{3}$ & 0.5 & 0.5 & - & 0.15 \\
\hline $\mathrm{NaCl}$ & - & - & - & $8.55 \cdot 10^{-3}$ \\
\hline $\mathrm{AlCl}_{3} \cdot 6 \mathrm{H}_{2} \mathrm{O}$ & - & - & - & 0.45 \\
\hline $\mathrm{C}_{6} \mathrm{H}_{8} \mathrm{O}_{6}$ & 0.05 & 0.05 & - & - \\
\hline Sodium laurylsulfate & $5.55 \cdot 10^{-4}$ & $55 \cdot 10^{-4}$ & $0-55 \cdot 10^{-4}$ & $0-55 \cdot 10-4$ \\
\hline $\mathrm{NH}_{2} \mathrm{CH}_{2} \mathrm{COOH}$ & - & - & $2.66 \cdot 10^{-2}$ & $2.66 \cdot 10^{-2}$ \\
\hline Saccharin (mg/l) & $0-1000$ & $0-1000$ & - & - \\
\hline $\mathrm{pH}$ & 3.2 & 3.5 & 2.36 & $2.6-3.6$ \\
\hline$T^{\circ} \mathrm{C}$ & $25-40$ & $25-40$ & $20-25$ & $20-40$ \\
\hline
\end{tabular}

The deposited layers were analyzed by surface visualizing techniques like scanning electronmicroscope and atomic force microscope.

The efficiency of the nanocoatings was measured by electrochemical methods like potentiodynamic technique and electrode impedance spectroscopy.

\section{Results and discussion}

\subsection{Effect of the bath compositions}

The composition of the electrolyte has a great influence on the structure of the cathode. The influence of the additives in different solution on the nickel nanostructure is demonstrated in Figure 2. 


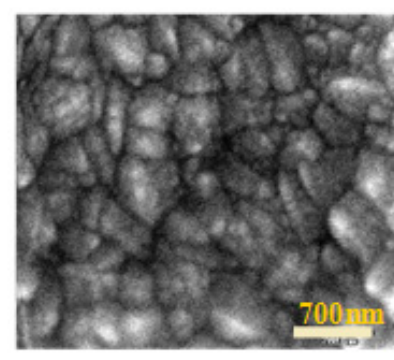

a, Watt's electrolyte

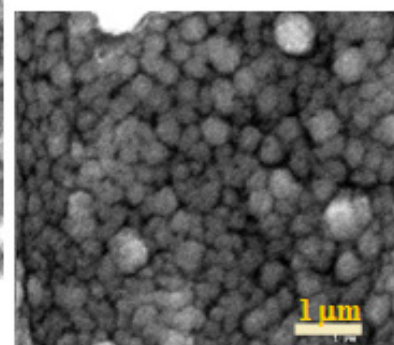

b, Watt's electrolyte + Sacharin

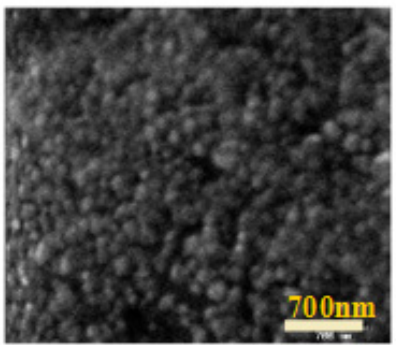

c, Watt's electrolyte + K-Na-tartarate

Figure 2. Influence of electrolyte composition on the Ni grain size.

Figure $2 \mathrm{a}$ shows the structure of deposit in the absence of additives, the average grain size is about $300 \mathrm{~nm}$. When the experiments were carried out in Watt's solution containing $\mathrm{Na}$ saccharin, the grain size was further reduced (Figure 2b). The smallest grain size was formed in case of K-Na-tartarate containing solution. In the presence of this additive smaller 40-70 $\mathrm{nm}$ size nuclei appeared (Figure 2c).

\subsection{The influence of pulse parameters}

In our experiments the influence of pulse parameters on the grain size of the deposits visualized by atomic force microscope (AFM) images are visible in Figure 3. By the variation of temperature the grain sizes could also be changed (Figure 4).

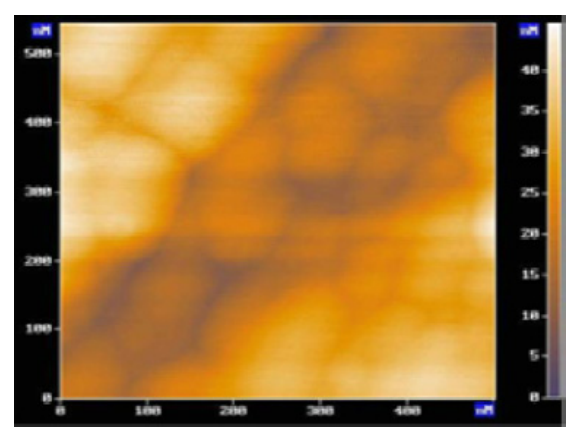

a

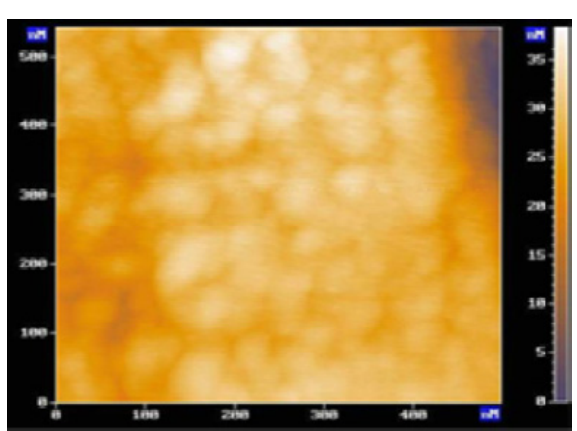

b

Figure 3. AFM images of nanostructured Ni coatings; $I_{\mathrm{p}}=0.5 \mathrm{~A} / \mathrm{cm}^{2} ; a: t_{\mathrm{off}}=250 \mathrm{~ms} ; b: t_{\mathrm{off}}=$ $100 \mathrm{~ms}$. 


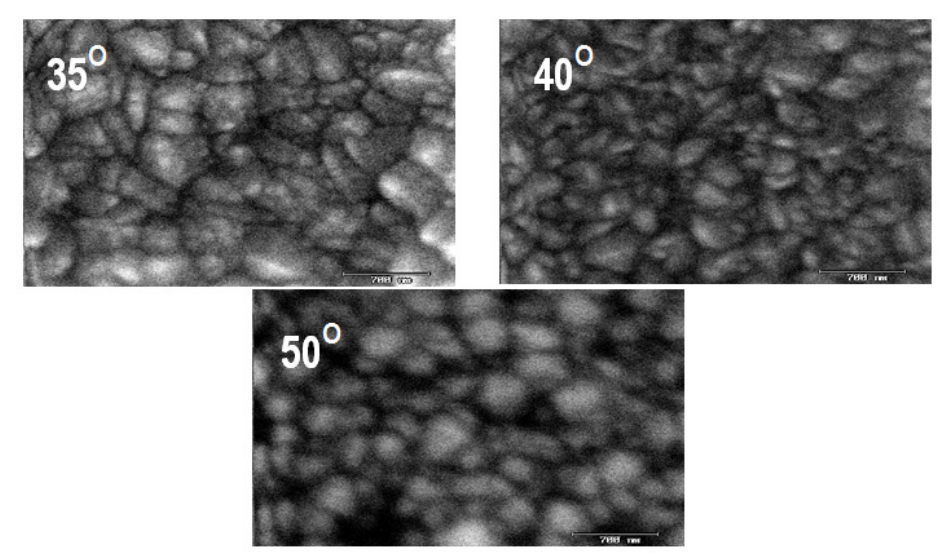

Figure 4. Influence of temperature on the grain size (Ni, Watt's electrolyte).

The parameters of the nickel deposition were determined that the period of on time was $1 \mathrm{~ms}$ in any case. Current density altered between 0.5 and $1 \mathrm{~A} / \mathrm{cm}^{2}, t_{\text {off }}$ varied between $100-250 \mathrm{~ms}$.

Due to our observation at the formation of smaller grain size at constant $0.5 \mathrm{~A} / \mathrm{cm}^{2}$ current density the shorter off time is preferred. At constant $t_{\mathrm{off}}=250 \mathrm{~ms}$ the grain size became smaller, when the current density decreases from $1 \mathrm{~A} / \mathrm{cm}^{2}$ to $0.5 \mathrm{~A} / \mathrm{cm}^{2}$.

\subsection{Characterization of the Fe deposits}

Systematic studies have been conducted to explore the influence of the electrodeposition parameters, including temperature the composition of solution and pulse parameters on the grain size. In these experiments $t_{\text {off }}$ was $250 \mathrm{~ms}$ and $t_{\mathrm{on}}$ was $1 \mathrm{~ms}$ in any case. The deposition has been carried out with pulsed current densities of $1 \mathrm{~A} / \mathrm{cm}^{2}$ and $2 \mathrm{~A} / \mathrm{cm}^{2}$. Table 2 summarizes the parameters of the depositions and the grain size of iron coatings. According to the SEM studies, smaller grain size was achieved at lower temperature independently from the composition of electrolytes. It was found that the coatings with the smallest grain size - less than $100 \mathrm{~nm}$ - could be obtained at room temperature from solution " 2 " and " 3 ".

Table 2. Pulse parameters, phosphorous content, and characteristic corrosion parameters $\left(E_{\text {corr }}, R_{\mathrm{p}}\right)$ of the iron-phosphorous layers.

\begin{tabular}{|c|c|c|c|c|c|c|c|}
\hline $\begin{array}{l}\text { Sample } \\
\text { type }\end{array}$ & $t_{\mathrm{on}}(\mathrm{ms})$ & $t_{\mathrm{off}}(\mathrm{ms})$ & $\begin{array}{c}I_{\mathrm{p}} \\
\left(\mathrm{A} \cdot \mathrm{cm}^{-2}\right)\end{array}$ & $\begin{array}{l}P \text { content } \\
(w t \%)\end{array}$ & $\begin{array}{c}I_{\mathrm{m}} \\
\left(\mathbf{m A} \cdot \mathrm{cm}^{-2}\right)\end{array}$ & $\begin{array}{c}\mathrm{E}_{\text {corr }}(\mathrm{mV}) \\
\text { vs. SCE }\end{array}$ & $\begin{array}{c}R_{p} \\
\left(\Omega \mathrm{cm}^{2}\right)\end{array}$ \\
\hline 1. & 2 & 9 & 0.05 & 9.00 & 9.09 & -649 & 660.9 \\
\hline 2. & 1 & 250 & 1 & 6.69 & 3.98 & -638 & 789.9 \\
\hline 3. & 1 & 100 & 1 & 6.07 & 9.91 & -680 & 43.4 \\
\hline 4. & 3 & 100 & 0.5 & 8.42 & 14.56 & -730 & 295.1 \\
\hline
\end{tabular}


Non-metallic impurities of deposit have been analysed by EDS measurements which showed some inclusion of adsorbed inhibitor molecule (S) and some impurities from those chemicals that were used to prepare the bath. In some cases $\mathrm{Cu}$ (from substrate) also contaminated the coatings. Due to these spectra, the impurity level of these elements is not significant.

We worked on producing Fe and Fe based nanostructured coatings and multilayers of soft magnetic materials with low coercivity and magnetic losses for high frequenciesapplications.

The iron layers have been produced by pulse current deposition onto $\mathrm{Cu}$ substrates. Here only 3 electrolytes of different compositions will be presented, Na-saccharin containing $\mathrm{Fe}$ (II) chloride and sulphate solutions, as well as citrate and magnesium sulphate based electrolytes.

$\mathrm{Ni}$ binary and ternary alloy coatings find possible industrial application in the field of corrosion protection, whereas pulse plating iron coating is a basic material for production of iron containing magnetic multi layer.

\subsection{Pulse plating of nano-srtuctured Ag coatings \\ Silver deposition for biomedical application}

Various surgial procedures require the use of implants. Such an implants may be Ti6Al4V alloy which is very strong and relatively light. However the bacterial adhesion and biofilm formation on these alloys can cause various human diseases.

Removing bacteria being in a biofilm is impossible and the local or systemic antibiotic treatment is not effective. In view of increasing bacterial resistance to antibiotics and antiseptics, silver coating can be an effective strategy to prevent the bacteria induced infections.

Moreover its antimicrobial activity combined with remarkably low human toxicity [9-10]. One important fact, which must be taken into account, is that, the silver ions have the antimicrobial effect, not the silver metal. Therefore it is very important to develop biocompatible antimicrobial coatings with a controlled $\mathrm{Ag}^{+}$ion release rate which should be effective for a long time, and should be low to avoid the toxic effect on body cells without hindering their excellent biocompatibility. The rate of silver release has been controlled in model solution - in vitro experiments using Electrochemical Impedance spectroscopy method. The EIS measurements were performed at open circuit potential.

\subsection{Pulse plating of Fe and Ni-based alloys $\mathrm{Fe}-\mathrm{P}$ alloys}

The interest for nanostructured and amorphous transition metals increased due to their specific magnetic, corrosion, and wear resistance properties [9]. The FeP layers have been deposited by pulse electrochemic technique from $\mathrm{NaH}_{2} \mathrm{PO}_{2}$ containing aqueous $\mathrm{FeSO}_{4}$ electrolyte at room temperature using $\mathrm{Pt}$ anode electrodes. Four groups of $\mathrm{FeP}$ samples were prepared at different pulse parameters. 
1. Pulse deposition conditions were close to the de deposition conditions

2. Pulse deposition conditions were set to the optimum conditions for deposition of nanostructured $\mathrm{Fe}$ from $\mathrm{FeSO}_{4}$ containing aqueous solution

3. Deposition parameters were the same as for sample 2 except the relaxation time was shortened

4. Relatively long deposition time combined with medium long relaxation time and current density

Amorphous and partly nanocrystalline/amorphous layers were deposited by pulse electrochemical technique from aqueous $\mathrm{NaH}_{2} \mathrm{PO}_{2}$ containing $\mathrm{FeSO}_{4}$ solution. The compositions are summarized in Figure 5.

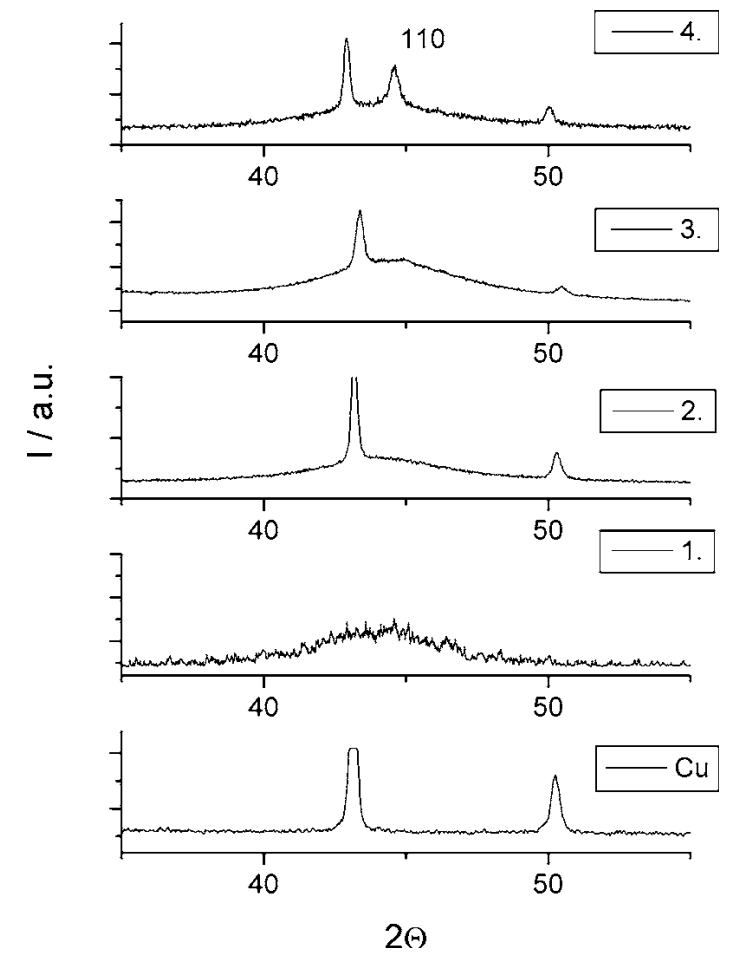

Figure 5. XRD patterns of $\mathrm{Cu}$ substrate and iron-phosphorous layers determined with $\mathrm{K} \mathrm{Cu}$ radiation. The numbers correspond to sample types as given in Table 2 .

A broad peak on each of the FeP XRD patterns indicated the presence of amorphous matrix and shows that structures sample 1 and sample 2 amorphous without any detectable nanocrystallites

\subsection{Anticorrosion effectiveness of the metal nanolayers}

The anticorrosion behaviour of the deposited layers is represented in case of $\mathrm{Fe}-\mathrm{P}$ layers. The electrochemical activity of a FeP layer was investigated by linear sweep measurements technique. Results are summarized in Figure 6. 


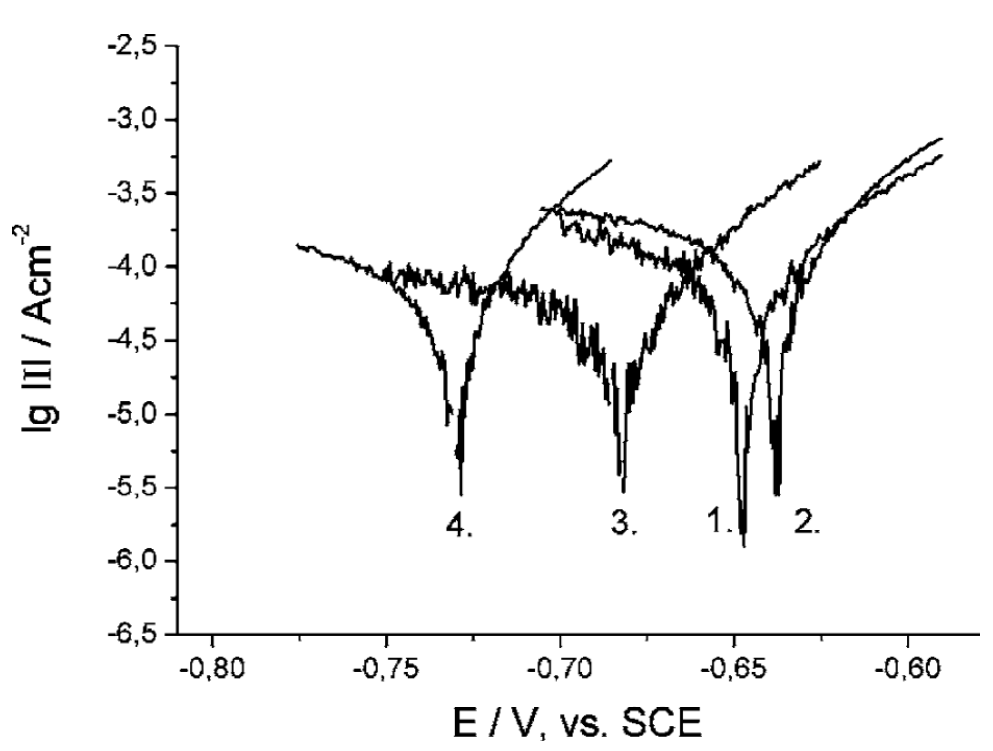

Figure 6. Linear sweep measurements on iron-phosphorous layers in Tafel plots in $0.1 \mathrm{M}$ $\mathrm{NaCl}$ at $\mathrm{pH} 5, v=12 \mathrm{mV} / \mathrm{min}$. No. for the sample identifications are given in Table 2.

Linear sweep voltammetry measurements conducted to characterize the corrosion behaviour of the layers show that the most positive corrosion potential shift was detected for the almost completely amorphous sample 2 , and the corrosion potential shifted to the negative direction with increasing amount of crystalline phase. The anodic curves for all samples look similar, indicating the similarity of the dissolution kinetics. Oxidation of $\mathrm{Fe}$ to $\mathrm{Fe}^{2+}$ was the common dissolution mechanism for all layers, resulting in similar anodic curves. The cathodic curves in the vicinity of the corrosion potential were affected by the reduction of oxygen, which is the rate-determining step.

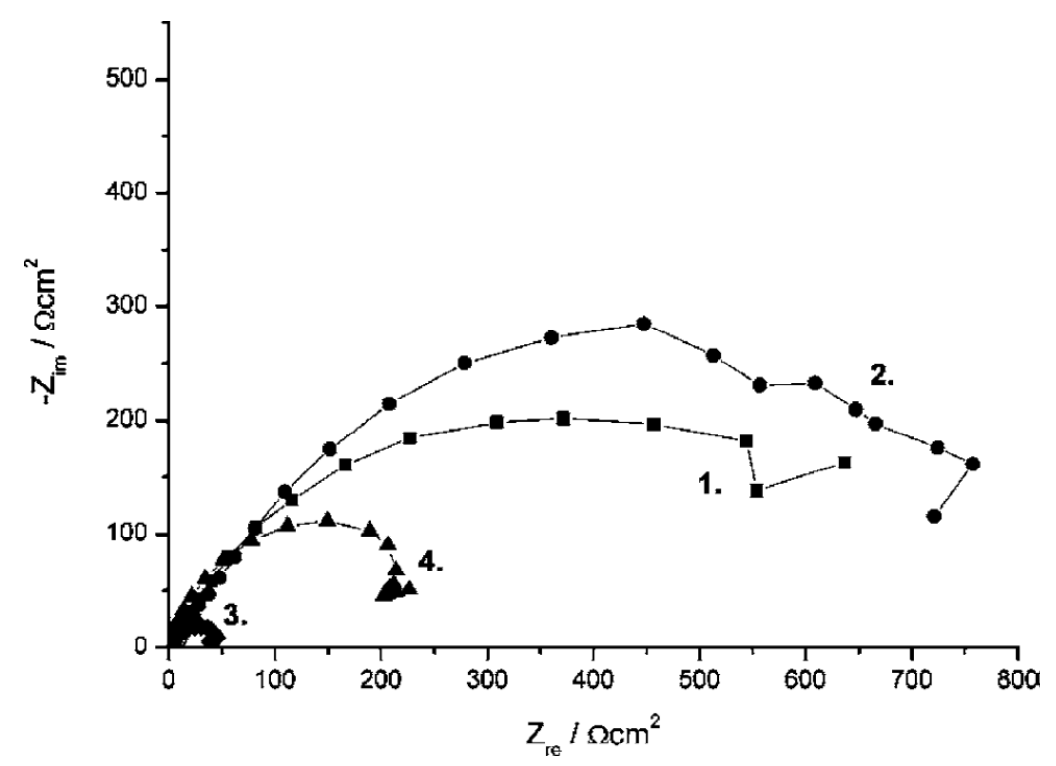

Figure 7. Impedance spectra plotted in Nyquist diagrams of iron-phosphorous deposits in $0.1 \mathrm{M} \mathrm{NaCl}$ solution at the corrosion potential. 
Amorphous and partly nanocrystalline/amorphous layers were deposited by pulse electrochemical technique from aqueous $\mathrm{NaH}_{2} \mathrm{PO}_{2}$ containing $\mathrm{FeSO}_{4}$ solution [10].

Polarization curves did not show clear linear Tafel regions; therefore, the polarization resistance was determined from "linear polarization" measurements, in addition to the data obtained from the electrochemical impedance spectroscopy (EIS). In these experiments, the potential was slowly scanned in the range of $\pm 5 \mathrm{mV}$ of the corrosion potential. $R_{\mathrm{p}}$ values were calculated from the slope of the applied potential vs measured current plots. These $R_{\mathrm{p}}$ values were in good agreement with the data determined from EIS measurements.

Amorphous layers with very few nanocrystallites have been deposited even at phosphorous content of $6.69 \mathrm{wt} \%$.

Electrochemical impedance spectra were measured on the iron-phosphorous deposits at the corrosion potential. Polarization resistance $\left(R_{\mathrm{p}}\right)$ was determined from the Nyquist semicircles (Figure 7). $R_{\mathrm{p}}$ values are summarized in Table 2. Polarization resistance values for sample 3 and 4 was most active layer and had the smallest polarization resistance while sample 2 exhibited the highest $R_{\mathrm{p}}$ value and showed the least electrochemical activity.

\subsection{Ni-Co alloy}

The PC technology can be successfully applied for deposition of binary alloys. The properties of the alloy deposits are usually superior to those of single metal electroplates. At this procedure the applied current periodically changes between a higher cathodic and zero current values or between a higher and a lower cathodic current densities. At higher cathodic current densities both of components deposited on the cathode surface, but during the $t_{\text {off }}$ period the more noble component was oxidized. The current peak is the sum of the partial current densities.

Pulse electrodeposition of $\mathrm{Ni}-\mathrm{Co}$ alloys was carried out to obtain adherent and compact surfaces with a controlled film thickness. Ni-Co alloys were deposited by applying current pulses with different pulse parameters on $\mathrm{Cu}$ substrates at $35^{\circ} \mathrm{C}$ from aqueous electrolyte. The morphology and the composition of the alloys were analysed by SEM and EDX, respectively.

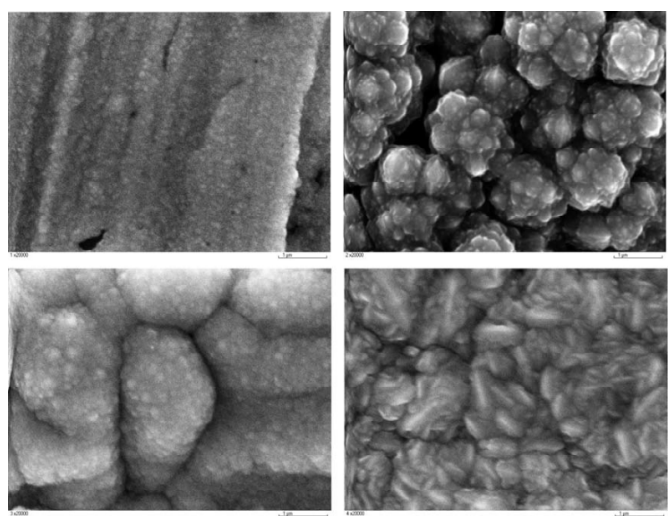

Figure 8. Influence of the pulse parameters on the alloy morphology at a constant on-time of $1 \mathrm{~ms}$. Pulse parameters used are presented in the micrographs and listed in the Table 1. 
Electrodeposition of $\mathrm{Ni}-\mathrm{Co}$ alloys was carried out from a chloride-based solution using analytical reagent grade chemicals.

The on-time $\left(t_{\text {on }}\right)$ was kept constant at a value of $1 \mathrm{~ms}$, whilst the off-time $\left(t_{\text {off }}\right)$ was set to either 50 or $250 \mathrm{~ms}$. A Pt sheet acted as the counter electrode.

The passive layer formation in $\mathrm{NaOH}$ solution was characterized by cyclic voltammetry measurement. In alkaline solution, the voltammograms showed the formation of $\mathrm{Co}(\mathrm{OH})_{2}$ and $\mathrm{CoOOH}$ as a function of the electrode potential. The anodic peaks, according to the formation of these oxides, reduced dramatically in the second cycle indicating the passivity of the Co-sites.

\section{References}

1. N. Ibl, Surf. Technol., 1980, 10, 81.

2. J.-C. Puippe and F. Leaman, Theory and Practice of Pulse Plating, AESF Publication, Orlando, 1986.

3. M.S. Chandrasekar and M. Pushpavanam, Electrochim. Acta, 2008, 53, 3313.

4. J.-C. Puippe and N. Ibl, J. Appl. Electrochem., 1980, 10, 775.

5. L. Peter, Q.X. Liu, Q.Z. Kerner and I. Bakonyi, Electrochim. Acta, 2004, 49, 1513.

6. L. Peter, J. Padar, E. Toth-Kadar, Á. Cziráki， P. Sóki， L. Pogány and I. Bakonyi, Electrochim. Acta, 2007, 52, 3813.

7. G. Nabiyouni, W. Schwarzacher, Z. Rolik and I. Bakonyi, J. Magn. Magn. Mater., 2002, 253, 77.

8. B. Tury, M. Lakatos-Varsányi and S. Roy, Surf. Coat. Technol., 2006, 200, 6713.

9. M. Lakatos-Varsányi, M. Furkó and T. Pozmann, Electrochim. Acta, 2011, 23, 7787.

10. A. Mikó, R. Hempelmann, M. Lakatos-Varsányi and E. Kálmán, Iron-Phosphorous Layers Deposited by Pulse Electrochemical Technique, Electrochem. Solid-State Lett., 2006, 9, C126. 